Article

\title{
Investigation of Liquid Metal Embrittlement during Resistance Spot Welding of Martensitic Steel with Zn Jet Vapor-Deposited Coating
}

\author{
Vojtech Kucera ${ }^{1,2, *(D)}$, Zuzana Zofkova ${ }^{1}$, Christopher DiGiovanni ${ }^{3}$, Liu He ${ }^{3}$ and Dalibor Vojtěch $^{1}$ \\ 1 Department of Metals and Corrosion Engineering, University of Chemistry and Technology, Technická 5, \\ 16628 Prague, Czech Republic; zofkovaz@vscht.cz (Z.Z.); vojtechd@vscht.cz (D.V.) \\ 2 Press Shop and Welding Shop Technical Service, ŠKODA AUTO a.s., tř. Václava Klementa 869, \\ 29301 Mladá Boleslav, Czech Republic \\ 3 Department of Mechanical and Mechatronics Engineering, University of Waterloo, \\ Waterloo, ON N2L 3G1, Canada; ctdigiov@uwaterloo.ca (C.D.); L39he@edu.uwaterloo.ca (L.H.) \\ * Correspondence: vojtech1.kucera@vscht.cz; Tel.: +42-07-0494-0236
}

Citation: Kucera, V.; Zofkova, Z.; DiGiovanni, C.; He, L.; Vojtěch, D. Investigation of Liquid Metal Embrittlement during Resistance Spot Welding of Martensitic Steel with $\mathrm{Zn}$ Jet Vapor-Deposited Coating. Metals 2021, 11, 1813. https:// doi.org/10.3390/met11111813

Academic Editor: Roberto Montanari

Received: 23 October 2021

Accepted: 9 November 2021

Published: 11 November 2021

Publisher's Note: MDPI stays neutral with regard to jurisdictional claims in published maps and institutional affiliations.

Copyright: (c) 2021 by the authors. Licensee MDPI, Basel, Switzerland. This article is an open access article distributed under the terms and conditions of the Creative Commons Attribution (CC BY) license (https:// creativecommons.org/licenses/by/ $4.0 /)$.

\begin{abstract}
Advanced high-strength steels protected by zinc coatings have contributed to a reduction in $\mathrm{CO}_{2}$ emissions in the automotive industry. However, the liquid metal embrittlement (LME) of the $\mathrm{Fe} / \mathrm{Zn}$ couple induced by simultaneously acting stresses and high temperatures during resistance spot welding could be the cause of unexpected failure. We investigated the possible risk of LME in spot-welded martensitic steel with $\mathrm{Zn}$ jet vapor-deposited coating and its influence on weld strength. The weld nugget cross-sections were analyzed (optical microscopy, SEM-EDS), and their tensile shear strengths were compared with their uncoated counterparts. LME cracks were observed in all samples meeting the process window $(6,6.5,7 \mathrm{kA})$ located at the edge of the sheet/electrode indentation area. The frequency and length of cracks increased with current, and the occurrence of $\mathrm{Zn}$ within cracks indicated the LME mechanism. The shear tests showed the $\mathrm{Zn}$-coated sample underwent a decrease in tensile shear strength that was most evident at a welding current of $7 \mathrm{kA}$ $(13.2 \%)$. However, LME was excluded as a cause of lower strength. The decrease was attributed to the smaller nugget diameter and the thin slit of $\mathrm{Zn}$ coating remaining in the weld notch.
\end{abstract}

Keywords: liquid metal embrittlement; resistance spot welding; jet vapor deposition; martensitic steel

\section{Introduction}

Continuously stricter $\mathrm{CO}_{2}$ emission limits are changing the material concept in the automotive industry, leading to an increase in advanced high-strength steels (AHSS) implemented in the car body. The development of AHSS with higher strength has enabled reductions in sheet thickness and thus reductions in the body-in-white overall weight. Zinc coatings that provide cathodic protection to the steel are used as primary corrosion protection. However, the Fe-Zn couple is known to be susceptible to liquid metal embrittlement (LME) when the material is subjected to both high temperatures and stresses. A case in which both conditions are met is resistance spot welding (RSW) [1,2].

The assembled body-in-white contains approximately 5000-8000 spot welds [3], making RSW a leading sheet metal joining technology. The principle of RSW consists of clamping two or more steel sheets with a pair of copper electrodes, through which the current passes. The heat necessary for the joint formation is generated by the Joule heating effect, which can be quantified by the following equation:

$$
Q=\int_{0}^{\tau} I^{2}(\tau) \cdot R(\tau) \cdot d \tau[J]
$$

where $Q$ is Joule heat, $I$ is current, $\tau$ is time, and $R$ is resistance [4]. Ideally, heat is generated at the faying interface, leading to the heating and subsequent melting of the sheet/sheet 
interface with the simultaneous action of electrode forces. Softening and melting enable deeper penetration of the electrodes, increasing the contact area. After the current stops passing, the sheets are cooled using water-cooled copper electrodes, and a weld nugget is formed [5-7]. Therefore, the necessary conditions of high temperature and stresses are met during the RSW process, creating suitable conditions for LME [8,9].

LME is a phenomenon known for decades, and it has been observed for specific solid/liquid metal couples, e.g., $\mathrm{Al} / \mathrm{Ga}, \mathrm{Ni} / \mathrm{Bi}, \mathrm{Cu} / \mathrm{Bi}$, and $\mathrm{Fe} / \mathrm{Zn}$ couples. Zn liquidassisted cracking at high temperatures was mainly observed in the galvanized presshardening of steel during direct hot stamping and detected in a few cases in spot-welded IF and mild steel [10-13]. However, certain types of AHSS showed increased susceptibility to LME. Hence, with an increasing proportion of AHSS in the body-in-white, LME has been intensively discussed in recent years [10,13-16]. The melting temperature of $\mathrm{Zn}$ is $419^{\circ} \mathrm{C}$, which is significantly exceeded during RSW of steel substrates [17]. Zinc diffuses with the contribution of applied stresses along the grain boundaries, which provide high diffusivity paths $[9,18-20]$. This causes a weakening and loss of material ductility, which results in decohesion and crack nucleation due to tensile stresses during RSW [13,21,22]. Despite the low melting point of $\mathrm{Zn}$, the decrease in ductility that occurs in LME, called the ductility trough, has been observed in the temperature range of 700 to $950{ }^{\circ} \mathrm{C}[8,13,14]$.

LME crack formation at the indentation edge and slope was observed by Zhanxiang Ling et al. during the RSW of hot-dip galvanized Q\&P980 steel [8]. The crack density increased with the welding current and decreasing electrode force. In [23], the authors described a decrease in LME crack size with increasing electrode force in galvanized TRIP steel. A larger electrode contact area led to an increase in the cooling rate and a decrease in the peak temperature. The influence of LME on the weld strength of AHSS was studied by DiGiovanni et al. [21]. The authors observed a $43.6 \%$ reduction in the weld lap shear strength of galvanized TRIP1100 steel in comparison to its uncoated counterpart and different fracture paths. However, such a significant decrease in lap shear strength was only observed for galvanized TRIP1100. DP980 and TRIP690 did not show a similar decrease. In contrast, Kim et al. [24] showed a longer fatigue life of the TRIP steel sample despite the occurrence of LME cracks. However, the compared samples were welded with different currents (8.4 and $12 \mathrm{kA}$ ), and thus differed significantly in terms of weld nugget size. Bhattacharya [13] noted a possible increasing of sensitivity to LME cracking with increasing strength of steel, especially with strengths exceeding the tensile strength of $1000 \mathrm{MPa}$, and the possible influence of coating type on LME.

The abovementioned studies $[8,21,23,24]$ corroborate the findings of the Bhattacharya study [13], which stated the higher susceptibility to LME of steels with strengths over $1000 \mathrm{MPa}$ in combination with galvanized coatings. Moreover, the results of these studies indicate the important influence of other parameters, such as coating type, current, and weld nugget diameter, when assessing the severity of LME. The martensitic steel (MS) reaches strengths up to $2000 \mathrm{MPa}$ and thus meets the requirements for safety components of a lightweight car body. Thus, the quality and strength of the welds is critical for their implementation in the car body. This study extends the research works performed on LME with another couple of martensitic steel and a nonconventional $\mathrm{Zn}$ jet vapor-deposited coating. The possible occurrence of LME could be the cause of unexpected failure, which is undesirable, especially for safety components. The influence of the $\mathrm{Zn}$ coating on the strength was investigated not only in terms of LME, but also other parameters, such as the nugget diameter and the type of failure with a significant effect on the strength, were examined. These parameters are often not considered.

\section{Materials and Methods}

The investigated material was commercially available martensitic steel with a thickness of $1.5 \mathrm{~mm}$ and a zinc coating applied by jet vapor deposition on both sides. The chemical composition of the bare steel measured by the Bruker G8 Galileo optical emission spectrometer (OES, Billerica, MA, USA) is given in Table 1, and the mechanical properties 
are given in Table 2. The samples for microstructure observation were prepared with standard metallography procedures, including grinding, polishing, and etching the samples using Nital reagent to reveal the steel microstructure and $10 \mathrm{wt}$. \% NaOH for $\mathrm{Zn}$ coating observation. The microstructure was studied by scanning electron microscopy (SEM, Tescan Lyra, Brno, Czech Republic) equipped with an energy-dispersive spectrometer (EDS, Oxford Instruments, $80 \mathrm{~mm}^{2}$, Abingdon, UK). The phase composition of the coating and coating/substrate interface was examined by XRD analysis. X-ray powder diffraction data were collected at room temperature with an X'Pert PRO $\theta-\theta$ powder diffractometer (PANanalytical, Almelo, Netherlands) with parafocusing Bragg-Brentano geometry using $\mathrm{CoK}_{\alpha}$ radiation $(\lambda=1.79028 \AA, \mathrm{U}=35 \mathrm{kV}, \mathrm{I}=40 \mathrm{~mA})$. The data were scanned with an ultrafast detector $X^{\prime}$ Celerator (or with a scintillator detector equipped with a secondary curved monochromator) over the angular range of 5-60 $(2 \theta)$ with a step size of $0.017^{\circ}$

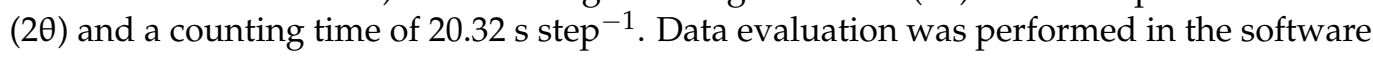
package HighScore Plus 4.0.

Table 1. Chemical composition of the martensitic steel (MS) measured by OES.

\begin{tabular}{cccccccccc}
\hline wt. \% & C & Si & Mn & P & S & Al & Cr & Ti & B \\
\hline MS & 0.2 & 0.24 & 1.8 & 0.012 & 0.0016 & 0.034 & 0.17 & 0.035 & 0.003 \\
\hline
\end{tabular}

Table 2. Mechanical properties of the martensitic steel (MS) measured by the uniaxial tensile test.

\begin{tabular}{cccc}
\hline Material & $\begin{array}{c}\text { Yield Strength } \\
\mathbf{( M P a )}\end{array}$ & $\begin{array}{c}\text { Ultimate Tensile Strength } \\
\text { (MPa) }\end{array}$ & $\begin{array}{c}\varepsilon \\
(\mathbf{\%})\end{array}$ \\
\hline MS & $1374 \pm 5$ & $1567 \pm 2$ & $6.0 \pm 0.7$ \\
\hline
\end{tabular}

The welding experiments were carried out with a medium-frequency direct current (MFDC, Centerline, Windsor, Canada) 144/180-kVA spot welder with a Bosch control timer. Forged welding electrodes 39D 1978-2 with a clamping area diameter of $16 \mathrm{~mm}$ and a contact area diameter of $5 \mathrm{~mm}$ from A2/2-CuCr1Zr were used in this study. The welding parameter setup was based on the literature and was experimentally optimized for the spot welder (Table 3). Subsequently, the cross-sections of the weld nuggets were examined by optical microscopy (Olympus GX71, Olympus, Tokyo, Japan) and the aforementioned scanning electron microscope with an energy-dispersive spectrometer. The strength tensile shear tests of the welded samples were carried out using the universal testing device LabTest 6.100.1.10. (LaborTech, Opava, Czech Republic). Vickers microhardness was measured using the automated microhardness tester Falcon 600 (Innovatest, Maastricht, The Netherlands), with the evaluation software IMPRESSIONS. The uncoated samples were prepared by dissolving the $\mathrm{Zn}$ coating in 50 vol. $\% \mathrm{HCl}$ with the addition of $\mathrm{C}_{6} \mathrm{H}_{12} \mathrm{~N}_{4}$ to preserve the original surface morphology. The uncoated samples for tensile shear tests were welded with the same parameters and had the same dimensions. The weld nugget diameter was measured with a digital microscope (Keyence VHX-7000, Keyence, Osaka, Japan).

Table 3. Welding parameters used in this study.

\begin{tabular}{ccccc}
\hline $\begin{array}{c}\text { Electrode Force } \\
\text { F (kN) }\end{array}$ & $\begin{array}{c}\text { Current } \\
\mathbf{I}(\mathbf{k A})\end{array}$ & $\begin{array}{c}\text { Time } \\
\boldsymbol{\tau}(\mathbf{m s})\end{array}$ & $\begin{array}{c}\text { Squeeze Time } \\
\boldsymbol{\tau}(\mathbf{m s})\end{array}$ & $\begin{array}{c}\text { Hold Time } \\
\boldsymbol{\tau}(\mathbf{m s})\end{array}$ \\
\hline 3.5 & $6,6.5,7$ & 350 & 500 & 200 \\
\hline
\end{tabular}

\section{Results and Discussion}

\subsection{Material Characterization}

The microstructure of the $\mathrm{Zn}$ coating was investigated before the welding experiments. A $\mathrm{Zn}$ coating with a thickness of $8.5 \pm 0.4 \mu \mathrm{m}$ was jet vapor-deposited on both sides of 
the steel sheets and copied with the original surface morphology of the steel (Figure 1a). The coating consisted of a homogenous Zn layer without the presence of any binary intermetallic phases or a diffusion layer at the coating/substrate interface. Moreover, the interface showed a sharp decrease in the concentration of Zn (Table 4), which was confirmed by SEM-EDS mapping of the element distribution (Figure 1b). A small amount of oxygen was detected near the top-surface layer of the coating (Table 4). However, it cannot be clearly determined whether the detected oxygen originated from the oxide layer or from the residues of oxygen in the gap between the sample and the resin. The microstructure of the coating (Figure 1a) revealed a preferential crystalline orientation after etching in $10 \mathrm{wt}$. \% NaOH, which is probably related to the orientation of the steel surface. This preferential orientation of the Zn coating was further confirmed by strengthening the lines of crystalline planes (102) and (103) detected by X-ray diffraction (Figure 2). The explanation is supported by the high mobility of deposited atoms on the surface, allowing the migration of atoms and the growth of suitably arranged planes [25]. Preferential orientation in the [002] crystallographic direction of PVD coating ZnAl5 was also observed by Baker et al. [25]. Park et al. [26] described the influence of pressure on the crystal growth of PVD Mg thin films. Plane (101) was preferred over plane (002) with increasing pressure.

Only the presence of the Zn phase (JCPDS card no 04-007-2123) and Fe phase (JCPDS card no 04-007-2123) was detected by X-ray diffraction analysis. The Fe clearly originated from the steel substrate, indicating sufficient penetration of $\mathrm{X}$-ray radiation through the entire volume of the measured coating. This can be supported by Ghanbari [27], who calculated the penetration depth of $\mathrm{X}$-ray radiation in an Fe- $\mathrm{Zn}$ system. The penetration depth was $20 \mu \mathrm{m}\left(2 \theta=45^{\circ}\right)$ for $\eta-Z n$ and $3.6 \mu \mathrm{m}\left(2 \theta=45^{\circ}\right)$ for $\alpha$-Fe. The absence of binary intermetallic phases corroborates the results of the SEM-EDS analysis.

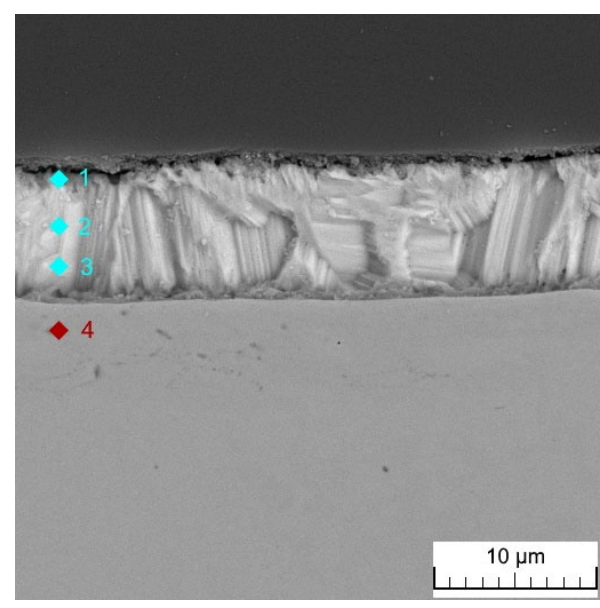

(a)

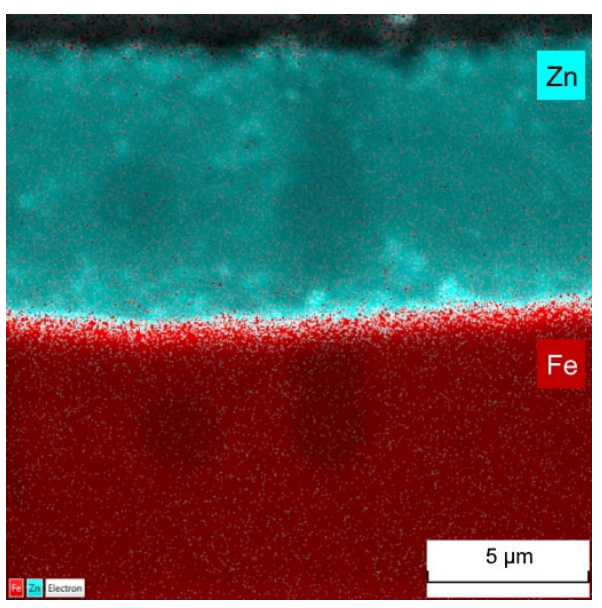

(b)

Figure 1. The microstructure of the $\mathrm{Zn}$ jet vapor-deposited coating etched in $10 \mathrm{wt}$. \% of $\mathrm{NaOH}$ (a) and SEM-EDS element distribution map (b).

Table 4. Results from the SEM-EDS chemical point analysis, presented as atomic percentages.

\begin{tabular}{ccccccc}
\hline Spectrum & Zn & Fe & Mn & Cr & Si & O \\
\hline point 1 & 90.9 & 1.7 & - & - & - & 7.4 \\
point 2 & 97.8 & 2.2 & - & - & - & - \\
point 3 & 97.1 & 2.9 & - & - & - & - \\
point 4 & 0.7 & 96.9 & 1.9 & 0.2 & 0.3 & - \\
\hline
\end{tabular}




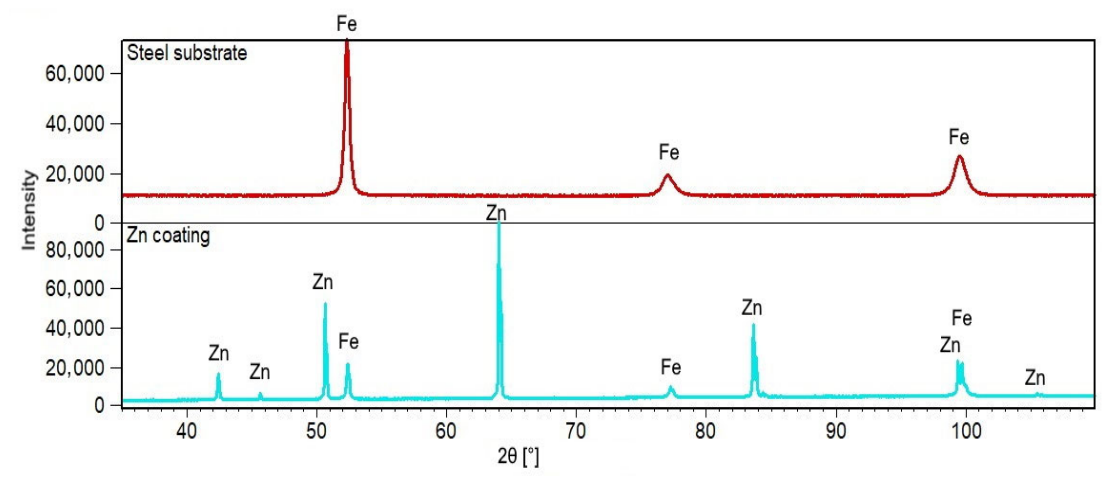

Figure 2. XRD pattern of the substrate martensitic steel and steel with the applied Zn coating.

\subsection{Locations of LME Cracks}

The current range curve (Figure 3) obtained using the ISO 14327 standard with the lower limit determined by $3.5 \sqrt{ } \mathrm{t}(\mathrm{t}$ - thickness of the sheet) and expulsion as the upper limit shows the proportional relation between the weld current and nugget diameter. The nugget started to form between 4.5 and $5 \mathrm{kA}$ and grew with increasing welding current until expulsion occurred (marked with empty squares in Figure 3). The acceptable nugget diameters were formed in the range of 6 to $7 \mathrm{kA}$ and were further investigated in terms of possible LME. In $[8,13,14,23]$, the authors identified three possible types of LME cracks according to their location: (i) the first type of LME crack is located at the edge of the sheet/electrode indentation area, which is the most frequently described crack in the literature [13,23,28-30]; (ii) the second type occurs at the steel/electrode contact interface and sometimes extends to the weld nugget region; (iii) in a few cases, the third type of LME crack is observed at the sheet-to-sheet interface where the melted $\mathrm{Zn}$ coating is ejected to the weld notch by the acting electrode force. The crack then propagates vertically to the interface through the thickness direction. All three possible types of LME cracks in their locations are indicated by red lines in Figure 4, and these locations were examined in spot weld cross-sections of martensitic steel with a jet vapor-deposited Zn coating.

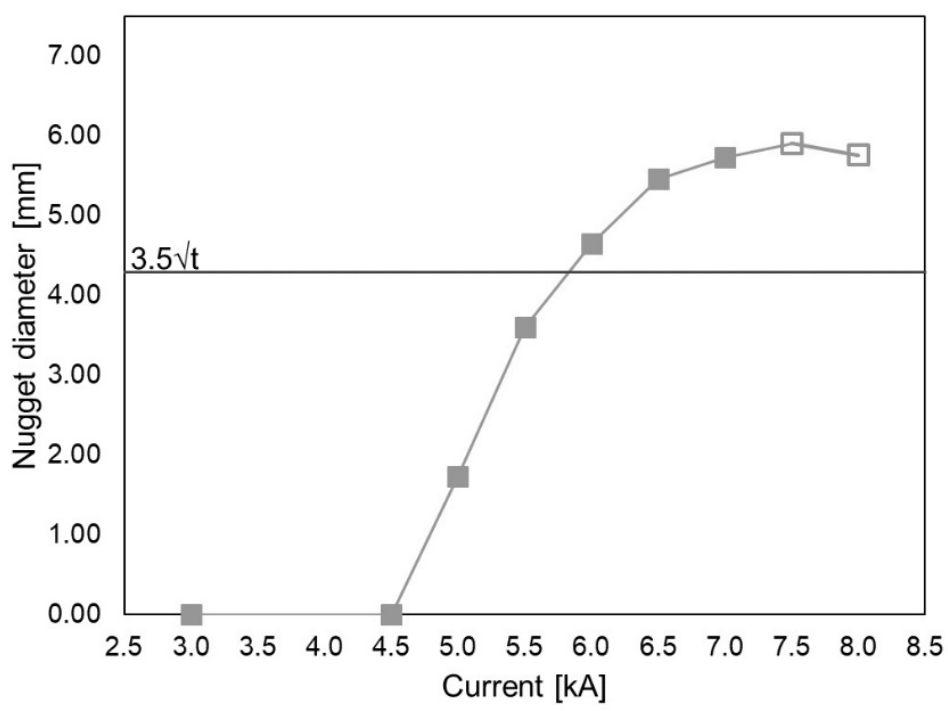

Figure 3. Current range curve with a $0.5 \mathrm{kA}$ step for martensitic steel with a $\mathrm{Zn}$ jet vapor-deposited coating in accordance with ISO 14327 conditions. 


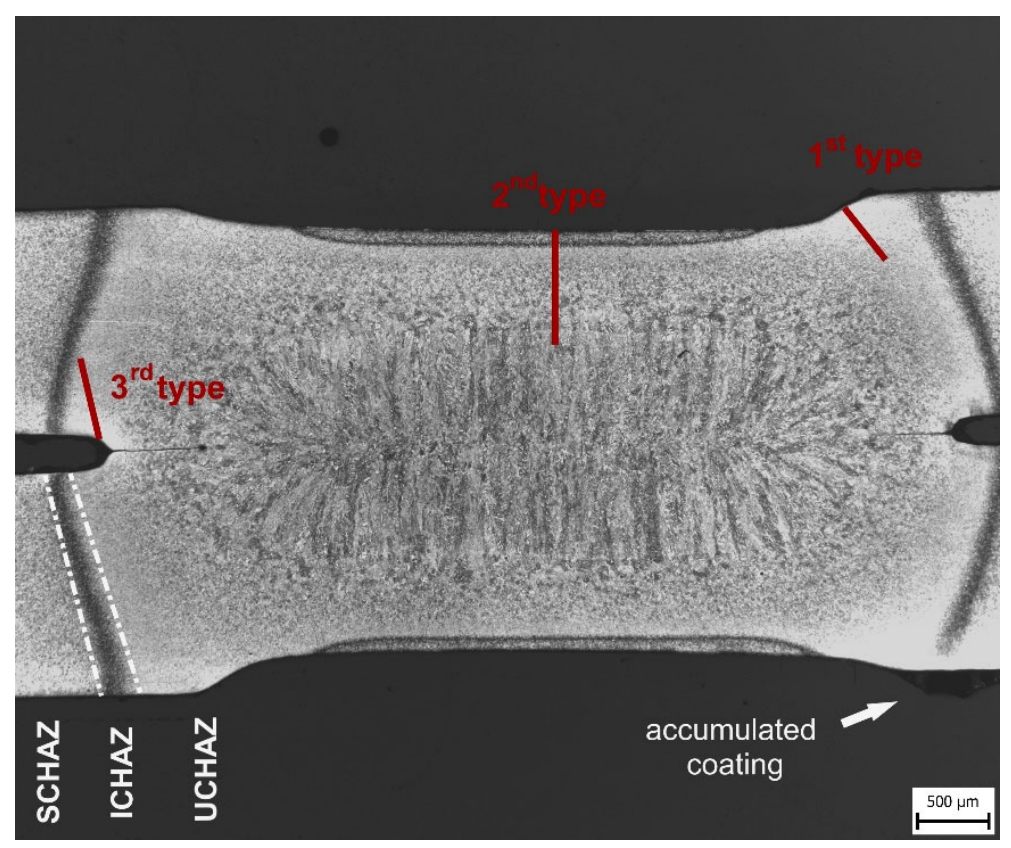

Figure 4. Typical macrostructure of the weld nugget of resistance spot welded martensitic steel with marked LME-sensitive locations. The current used for welding was $6 \mathrm{kA}$.

The cross-sections of the spot welds revealed a typical heterogeneous weld macrostructure (Figure 4). The fusion zone (FZ) expanding from the original faying interface was formed by coarse martensite laths oriented in the direction of rapid heat dissipation. The microstructure in the heat-affected zone (HAZ) followed the temperature gradient from the near vicinity of the FZ with the highest temperature to the cool base metal. Therefore, three HAZs can be clearly distinguished, typically referred to as the upper-critical heat affected zone (UCHAZ) consisting of martensite, the inter-critical heat-affected zone (ICHAZ) with a dual-phase microstructure of martensite and ferrite, and the sub-critical heat-affected zone (SCHAZ) formed by the tempered martensite of the base metal [31-34].

The significantly lower melting temperature of the $\mathrm{Zn}$ jet vapor-deposited coating $\left(419{ }^{\circ} \mathrm{C}\right)$ led to preferential melting at the faying interface and subsequent ejection to the weld notch [17]. A similar situation occurred on the surface of the steel in contact with the electrode. The coating was ejected to the electrode indentation edge and weld periphery, where it accumulated (Figure 4). It could be concluded that the Zn coating with a low

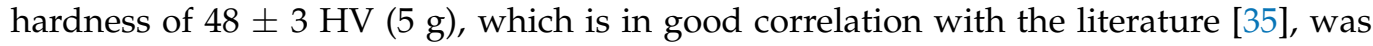
easily deformed by the electrodes and ejected beneath the electrode after melting. This accumulation at the edge of the sheet/electrode indentation area provided a sufficient amount of $\mathrm{Zn}$ liquid that, together with the tensile stresses caused by volume changes due to the temperature gradient, created suitable conditions for LME cracking (marked as first type localization) $[13,36]$. Hence, these critical areas were investigated in detail by optical microscopy (Figure 5). The samples welded with a current of $6 \mathrm{kA}$ did not show any signs of LME cracks. However, increasing the current to 6.5 and $7 \mathrm{kA}$ led to the occurrence of cracks in this critical area, described as the first type-the edge of the sheet/electrode indentation area [37]. The number and length of cracks significantly increased between $6.5 \mathrm{kA}$ and $7 \mathrm{kA}$, and they were found in all four areas of sheet/electrode indentation edges. The length of the cracks was measured from the bottom to the tip of the crack in the direction perpendicular to the surface, and the measured values varied in a wide range from 18 to $82 \mu \mathrm{m}$. The second and third types of LME cracks were not observed in this study. 


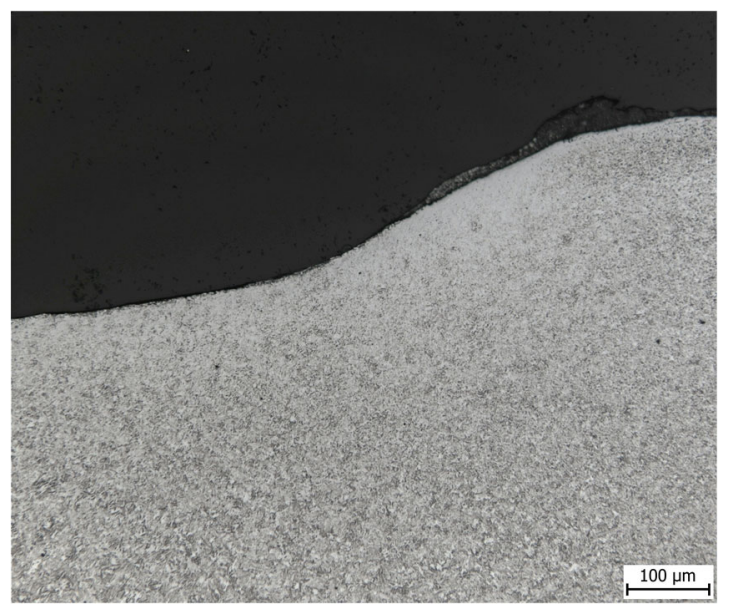

(a)

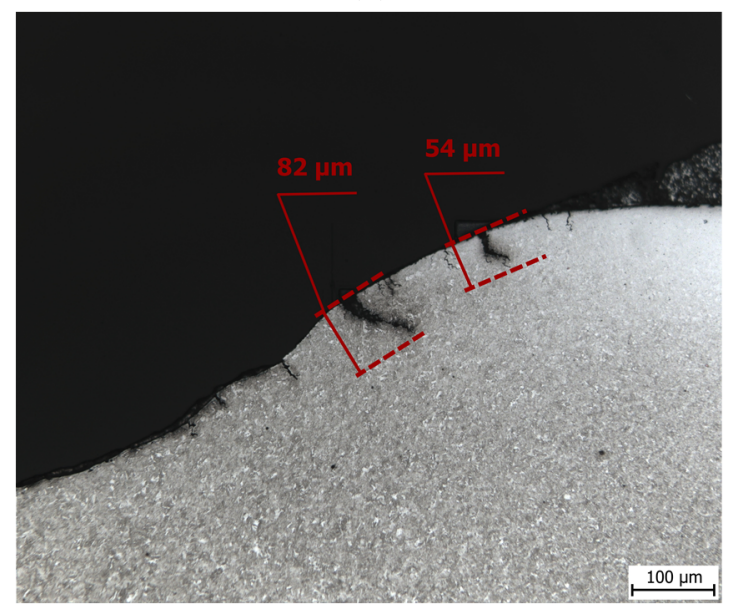

(c)

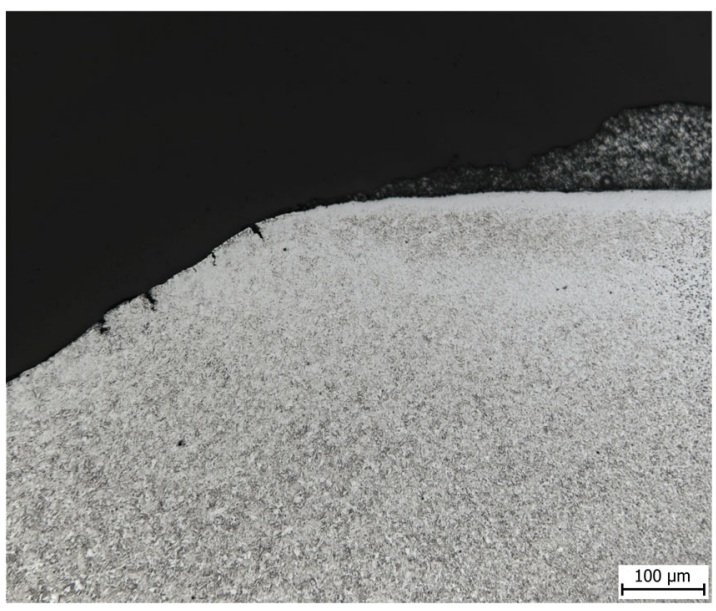

(b)

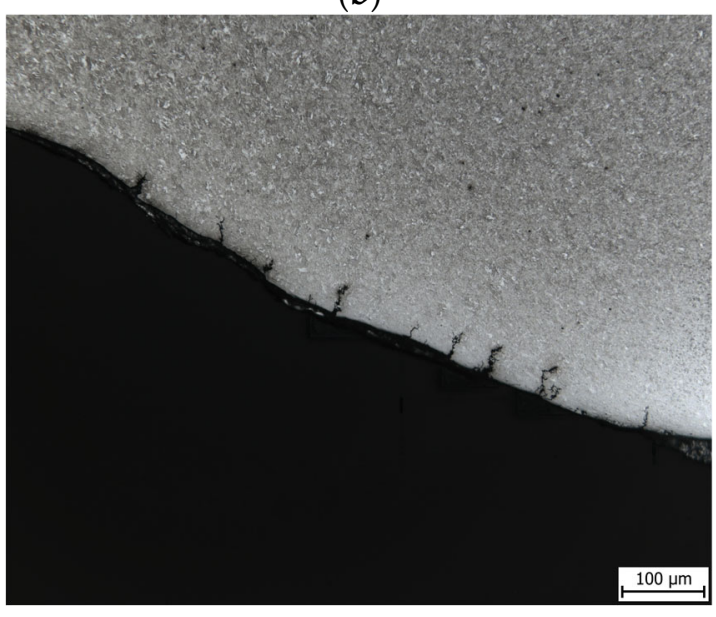

(d)

Figure 5. Detailed microstructure of critical areas with potential risk of LME occurrence: (a) $6 \mathrm{kA},(\mathbf{b}) 6.5 \mathrm{kA}$, (c) $7 \mathrm{kA}$, (d) $7 \mathrm{kA}$.

The microstructure in the near vicinity of the cracks (Figure 5) consisted of fine martensite (UCHAZ) with a hardness of $543 \pm 9 \mathrm{HV} 0.5$, which was slightly higher than the hardness of the base metal with a martensitic microstructure (509 $\pm 9 \mathrm{HV} 0.5)$. The temperature in this area exceeded the transformation temperature $A_{c 3}$, resulting in austenite transformation. Subsequently, the high cooling rate and sufficient hardenability led to coarse martensite formation near the FZ and fine martensite formation near the surface (Figure 6) [34,38]. The fine martensitic microstructure of the steel with a carbon content of $0.2 \mathrm{wt}$. \% indicated that a temperature only just above $\mathrm{A}_{\mathrm{c} 3}$ was reached, which prevented the austenitic grains from coarsening while fulfilling the condition of a ductility trough (700-950 $\left.{ }^{\circ} \mathrm{C}\right)$ typical for LME $[8,13,14]$. In accordance with our results, the LME cracks that presented exclusively in the areas with fine martensite microstructure were described by Zhanxiang Ling et al. [8], who studied the susceptibility of hot-dipped galvanized quenching and partitioning (Q\&P) steel to LME cracking. The authors proposed an LME mechanism based on the diffusion model. This model assumes the diffusion of Zn atoms into the steel along the austenite grain boundaries and the transformation of the immediate vicinity of grain boundaries into ferrite, resulting in cohesion loss $[8,10,13,14]$. The diffusion was determined to be stress-assisted, and the critical role of stress in creating additional diffusion flux was highlighted in [9]. With increasing stress, the cracks open and are penetrated by $\mathrm{Zn}$ liquid through capillary forces. 


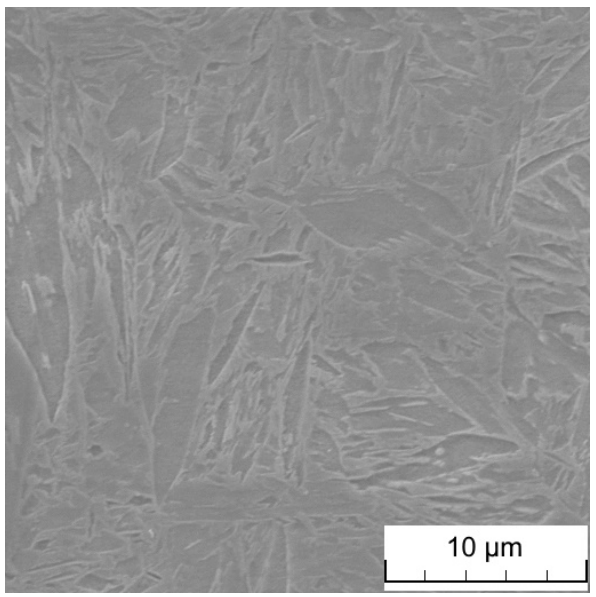

(a)

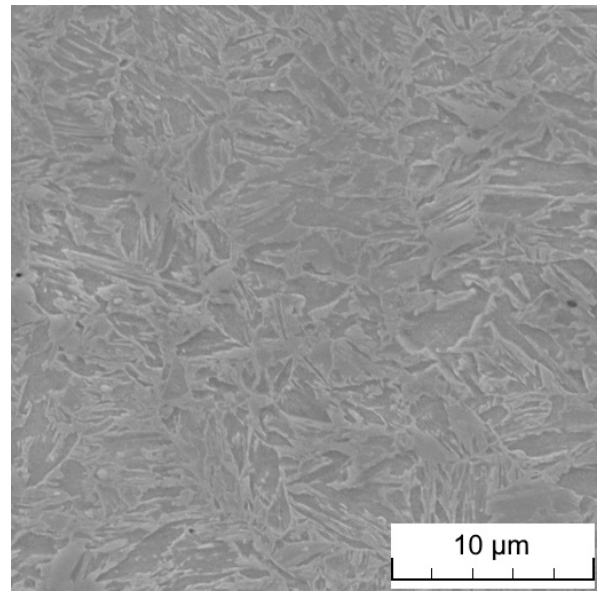

(b)

Figure 6. SEM micrographs of coarse-grained martensite (a) and fine-grained martensite (b) in the UCHAZ.

To confirm the LME mechanism as the cause of the observed cracks, SEM-EDS analysis was performed on unetched samples to avoid any dissolution of $\mathrm{Zn}$ by the etching reagent. Moreover, the SEM detailed analysis (Figure 7a) revealed microcracks at the edge of the sheet/electrode indentation area (first type) in the sample welded with a current of $6 \mathrm{kA}$, which were not detected by optical microscopy. Nevertheless, the frequency and length of the cracks were much lower than those in the cases of $6.5 \mathrm{kA}$ and $7 \mathrm{kA}$. The results from EDS mapping and point chemical analysis confirm the presence of $\mathrm{Zn}$ inside the cracks, as demonstrated in Figure 7 and Table 5. The $\mathrm{Zn}$ concentration decreased in the direction from the top of the crack (86.2 wt. \%) into the crack tip (77.1 wt. \%), and was lower than in the original $\mathrm{Zn}$ coating composition. The coating that penetrated the crack was significantly alloyed with Fe in the range of 13.3 to $22.1 \mathrm{wt}$. \% of Fe, which corresponds approximately to the composition of $\Gamma$ and $\delta \mathrm{Zn}$-rich phases [35]. Since the coating consisted of pure $\mathrm{Zn}$ in direct contact with the steel surface, the low melting temperature $\left(419^{\circ} \mathrm{C}\right)$ resulted in the early melting of the coating. The melted coating was then easily ejected to the edge of the sheet/electrode indentation area, where, combined with increasing temperature, it favored the diffusion of $\mathrm{Zn}$ along the fine austenite grain boundaries and Fe into the Zn-rich melt. During cooling, the Zn-rich melt underwent a peritectic reaction (peritectic temperature $\left.782{ }^{\circ} \mathrm{C}\right) \alpha-\mathrm{Fe}+\mathrm{L} \rightarrow \Gamma$, or possibly $\Gamma+\mathrm{L} \rightarrow \delta$. Therefore, the formation of the zinc-rich phases is evidence of a Zn-rich melt causing LME cracking $[8,13,35]$. The traces of copper probably originated from the wear of copper electrodes and their degradation during the welding process, leading to the alloying of the coating. This copper enrichment was observed in [24] and resulted in the formation of $\mathrm{Cu}-\mathrm{Zn}$ intermetallic phases at the edge of the LME cracks. Nevertheless, the $\mathrm{Cu}$ concentration was significantly higher than that measured in our work. Silicon and manganese arose from the steel substrate. 


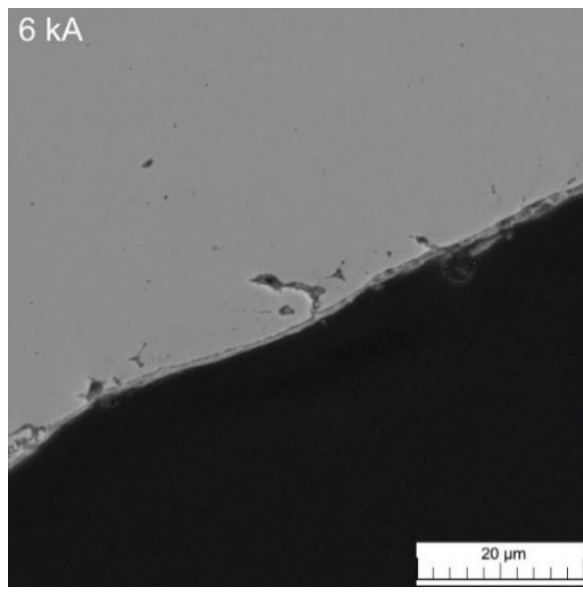

(a)
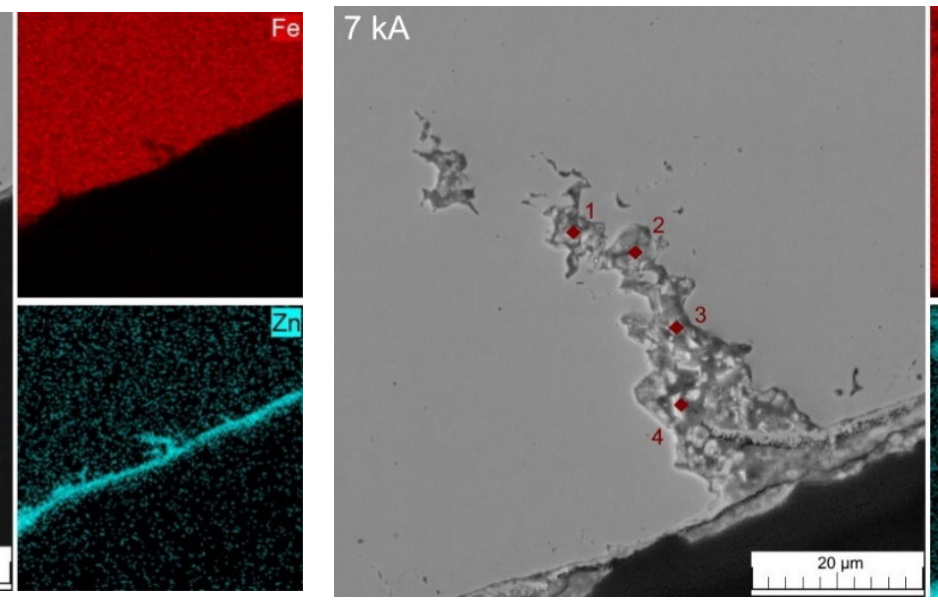

(b)

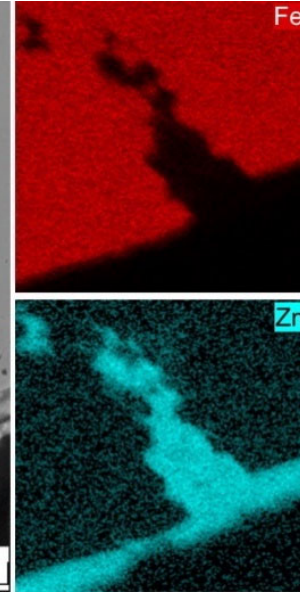

Figure 7. SEM micrographs of the LME cracks combined with the SEM-EDS element distribution maps: (a) 6 kA, (b) 7 kA.

Table 5. Results of SEM-EDS chemical point analysis (in wt. \%) of the inner part of the LME cracks.

\begin{tabular}{cccccc}
\hline Spectrum & Si & Mn & Fe & Cu & Zn \\
\hline point 1 & - & 0.3 & 22.1 & 0.5 & 77.1 \\
point 2 & - & 0.3 & 18.7 & 0.7 & 80.3 \\
point 3 & 0.2 & - & 14.4 & - & 85.4 \\
point 4 & 0.5 & - & 13.3 & - & 86.2 \\
\hline
\end{tabular}

\subsection{Tensile Shear Tests}

The major concern regarding welded safety components in the automotive industry is the strength of spot-welded parts. Therefore, tensile shear tests of the spot-welded $\mathrm{Zn}$ coated samples were carried out to investigate any possible detrimental influence of LME on shear strength. Furthermore, the results were compared to an uncoated counterpart welded with the same parameters. The shear strengths were lower for all coated specimens (Table 6), although other factors, such as nugget diameter and type of fracture, must be considered when evaluating the effect of the coating. In this particular case, the lower strength of the Zn-coated samples could be attributed to the smaller nugget diameter that correlates with lower shear strengths (Table 6). The sample welded with $6 \mathrm{kA}$ showed the largest difference in nugget size, which decreased with increasing current. This difference was caused by the lower resistivity of the $\mathrm{Zn}$ coating and the order of magnitude lower hardness, which led to a lower contact resistance and thus less heat generated in the weld with the same parameters [5,6]. Furthermore, the Zn coating had an influence on the type of fracture. While all uncoated samples showed a button pull-out fracture and tensile shear strength of $16.7 \mathrm{kN}$ and higher, the Zn-coated samples changed from interfacial fracture (IF, $6 \mathrm{kA}$ ) to interfacial fracture with button pull-out (IF with BP, $6.5 \mathrm{kA}$ ) and button pull-out fracture $(\mathrm{PF}, 7 \mathrm{kA}$ ) with tensile shear strength in the range of $14.5-16.2 \mathrm{kN}$. The IF is characteristic of a smaller nugget diameter with a lower load-bearing capacity beginning at the weld notch and propagating through the FZ. The IF exhibits brittle behavior, and thus, is usually undesirable [31,33,34,39]. The transition from IF to PF occurred at $6.5 \mathrm{kA}$ for the coated sample when a critical nugget size of $6.62 \mathrm{~mm}$ was reached, similar to that of the uncoated sample $(6.7 \mathrm{~mm})$ showing PF. Moreover, these samples $(6.5 \mathrm{kA} \mathrm{Zn} \mathrm{coated} \mathrm{and} 6 \mathrm{kA}$ uncoated) showed similar shear strengths. Despite the PF and relatively small difference in nugget diameters $(6.5,7 \mathrm{kA}$ uncoated and $7 \mathrm{kA} \mathrm{Zn}$ coated), the greatest reduction in tensile shear strength (Table 6) was observed for the Zn-coated sample welded with $7 \mathrm{kA}$, the sample that exhibited the largest frequency and length of cracks. Therefore, the fractured coated and uncoated samples welded with $7 \mathrm{kA}$ were chosen and were cross-sectioned and examined. 
Table 6. Results from the comparison of coated and uncoated samples examined by tensile shear tests (tensile shear strength-TSS, partial thickness fracture-PTF, button pull-out-BP, button pull-out fracture- $\mathrm{PF}$, interfacial fracture-IF).

\begin{tabular}{ccccc}
\hline Samples & TSS $\mathbf{( k N )}$ & $\begin{array}{c}\text { Nugget } \\
\text { Diameter }(\mathbf{m m})\end{array}$ & Fracture Type & $\begin{array}{c}\text { Drop of TSS } \\
\mathbf{( \% )}\end{array}$ \\
\hline 6 kA Zn coated & $15.3 \pm 0.5$ & $6.17 \pm 0.04$ & IF + PTF & 8.1 \\
6 kA uncoated & $16.7 \pm 0.9$ & $6.70 \pm 0.04$ & PF & \\
6.5 kA Zn coated & $16.2 \pm 0.5$ & $6.62 \pm 0.13$ & IF with BP + PF & 5.0 \\
6.5 kA uncoated & $17.1 \pm 0.2$ & $6.90 \pm 0.22$ & PF & \\
7 kA Zn coated & $14.5 \pm 0.9$ & $7.13 \pm 0.04$ & PF & 13.2 \\
7 kA uncoated & $16.7 \pm 1.5$ & $7.48 \pm 0.40$ & PF & \\
\hline
\end{tabular}

From the cross-sections of fractured welds, both types of fractures were bottom pullout (Figure 8). The size of the nugget was large enough to bear the tensile/shear load and prevent brittle IF [39]. The fracture was initiated from the weld notch acting as a stress concentrator and propagated through the coarse-grained martensite in the UCHAZ when exceeding the critical strength. After reaching the FZ, the fracture path changed directions and followed the boundary between the FZ and coarse-grained UCHAZ. This behavior corroborates other studies $[33,39]$. Sherepenko et al. $[40,41]$ described the hardness drop at this FZ/UCHAZ boundary caused by carbon and alloying element redistribution between austenite $/ \delta$-ferrite/melt. This very narrow area with reduced hardness can provide a preferential path for crack propagation. However, the path was not clearly demonstrated by measuring a conventional hardness line scan (Figure 9), which showed a typical profile with a hardness drop in the SCHAZ and ICHAZ [31,34]. The sudden sharp drop in hardness in the FZ was caused by the presence of pores at the original faying interface. The final breakdown occurred in the thickness direction of the UCHAZ in the area outside the detected LME cracks. Furthermore, area A of the fractured Zn-coated sample (Figure 8b) and area B of the weld notch of the unfractured Zn-coated sample (Figure 10) were more closely examined to provide an explanation for the lower strength.

The cross-sectional view of the welded unfractured sample $(7 \mathrm{kA})$ with $\mathrm{Zn}$ coating revealed the thin slit spreading to the weld nugget (Figure 10(B)). From the magnified image of this area (Figure 11a), two branches leading from the weld notch to the edge of the nugget are apparent. The branches were filled with $\mathrm{Zn}$ originating from the coating, with lengths of approximately 60 and $175 \mu \mathrm{m}$. When the load was applied, these slits could significantly contribute to the stress concentration in the notch and accelerate weld failure. However, these slits were in the direction of the original sheet-to-sheet interface, and therefore were not LME cracks, which are rare in this location and propagate vertically through the thickness direction. Moreover, analysis of the chemical composition of the fractured area A (Figure 11b) excludes the contribution of LME cracks at the edge of the sheet/electrode indentation area to the lower strength. Zinc was not observed along the fracture path, and only traces of zinc were detected on the surface of the electrode indentation area. These findings support results found by DiGiovanni et al. [42], who observed deterioration in the mechanical properties when the critical crack depth of $300 \mu \mathrm{m}$ was exceeded. Although the number of cracks was relatively high in our study and cracks were located in the critical area (electrode indentation periphery), the length of the cracks was below the critical level. The reason for the lower strength of the sample with $\mathrm{Zn}$ coating is the combination of a smaller nugget with lower load bearing capacity and a thin layer of coating in the weld notch that increases the stress concentration. 


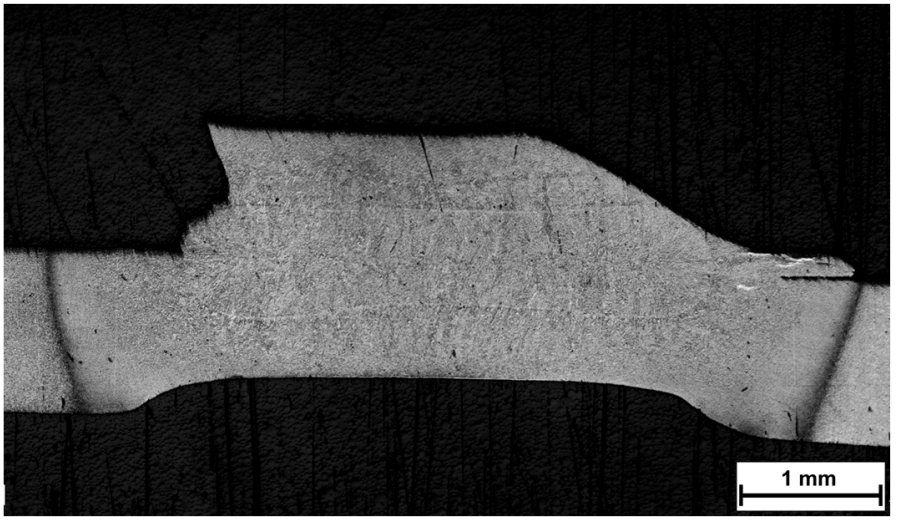

(a)

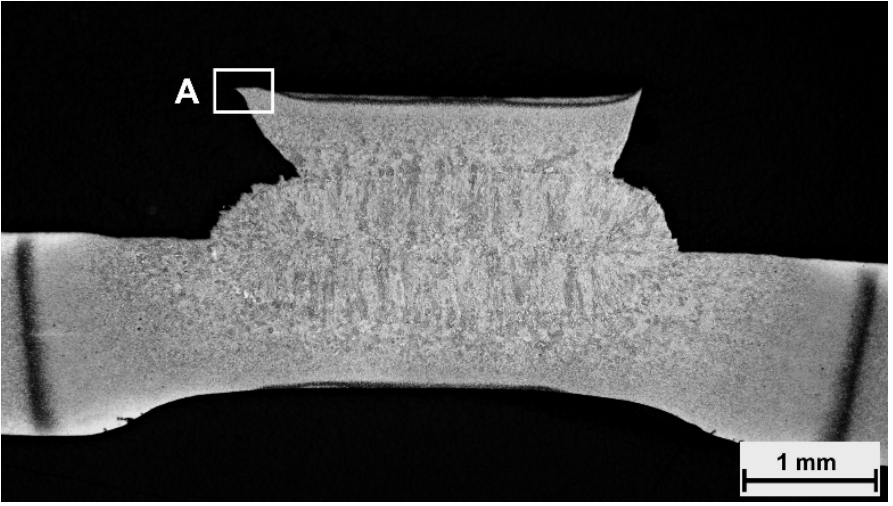

(b)

Figure 8. Cross-sections of welded and fractured martensitic steel showing the fracture morphology of the pull-out fracture: uncoated (a) and Zn-coated sample with a marked area, A, of SEM-EDS analysis (b).
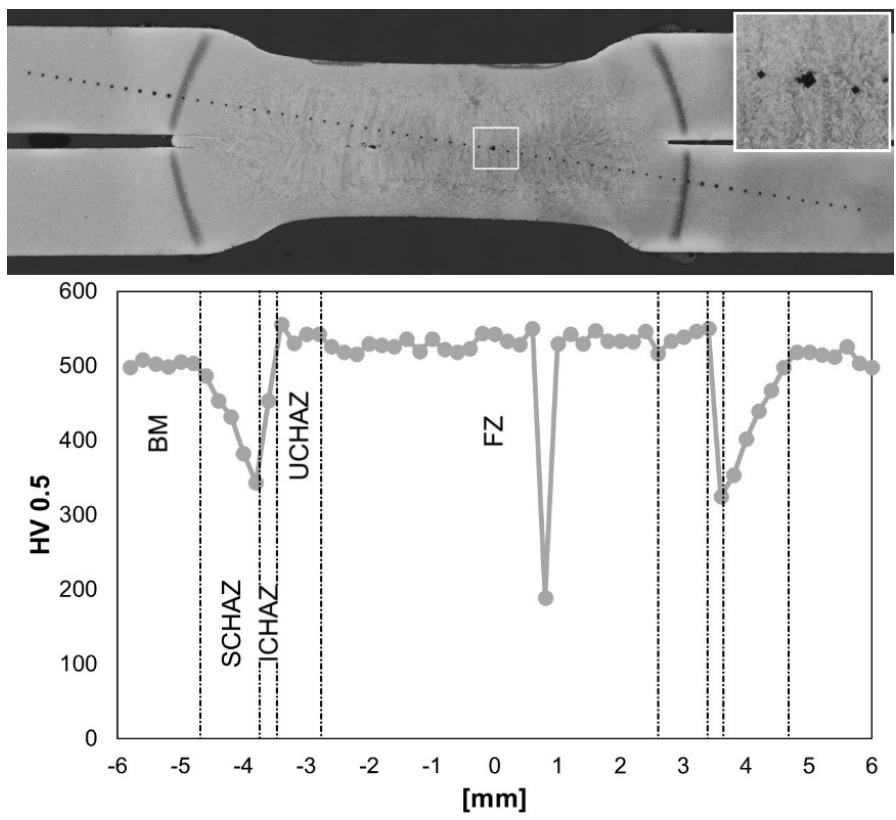

Figure 9. Microhardness profile in the cross-section of the weld joint (7 kA, Zn coated) with indication of the relevant heat-affected zones and detail of the pore at the original faying interface.

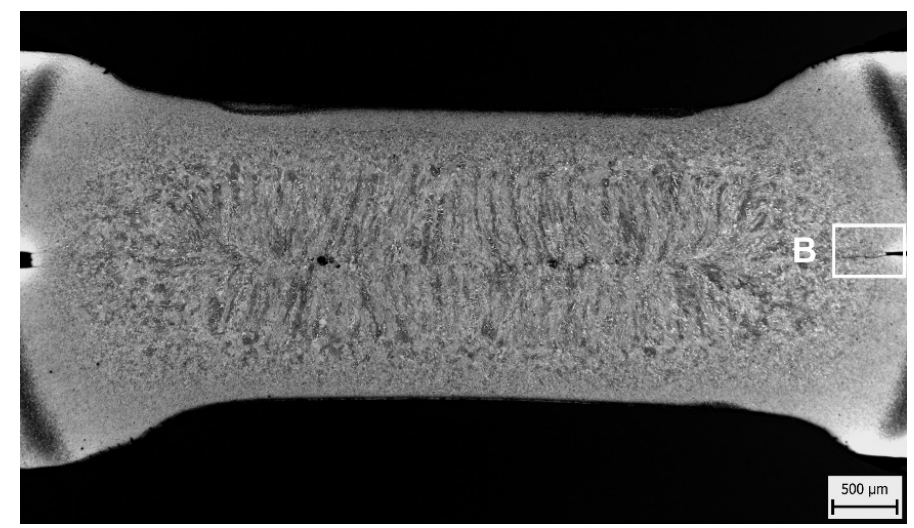

Figure 10. Cross-sectional view of the welded $\mathrm{Zn}$-coated sample $(7 \mathrm{kA})$ with a marked area, $\mathrm{B}$, of SEM-EDS analysis of the weld notch. 


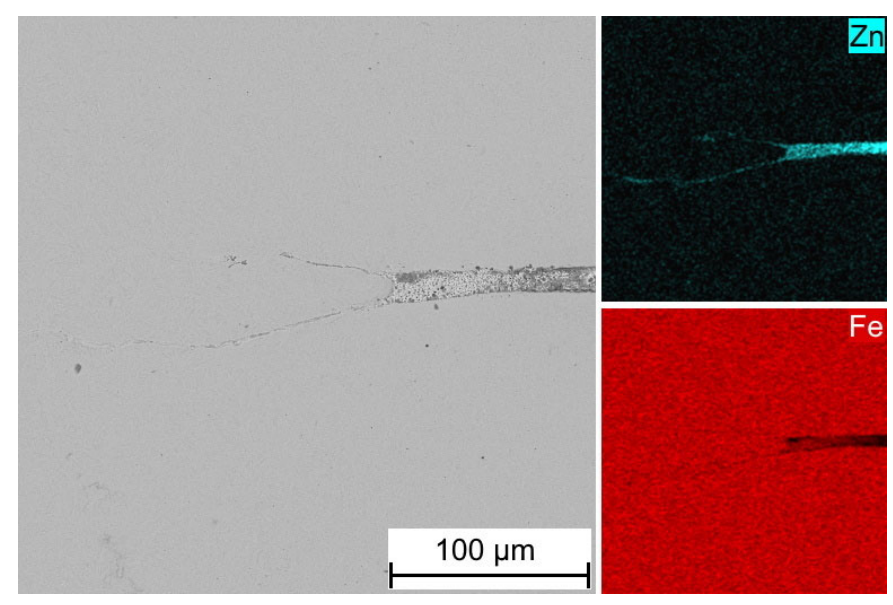

(a)

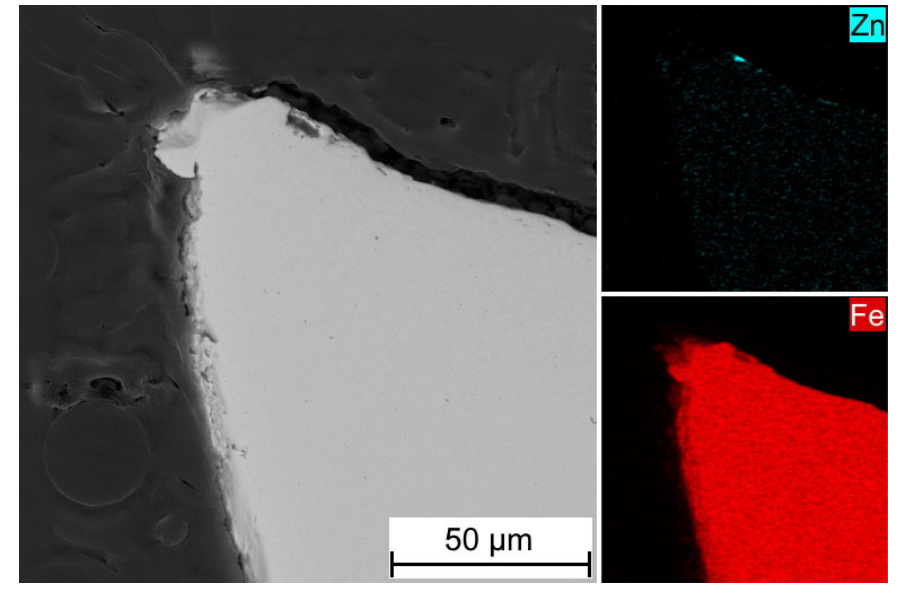

(b)

Figure 11. SEM details of magnified weld notch B (Figure 10) showing the branches filled with a thin layer of Zn coating (a) and the fracture cross section A (Figure 8 b) without any traces of $\mathrm{Zn}(\mathbf{b})$.

\section{Conclusions}

The liquid metal embrittlement of Zn-coated AHSS could be the cause of unexpected weld failure, which is highly undesirable, especially for safety components. Hence, we investigated resistance spot welds of martensitic steel with a $\mathrm{Zn}$ jet vapor-deposited coating. Welding experiments showed this combination of steel and coating at given welding parameters tends to result in LME cracks. LME cracks were present only in the location with the highest sensitivity to crack occurrence (first type). A high concentration of zinc inside the cracks confirmed the LME mechanism. The frequency and length of the cracks increased with the current.

The tensile shear tests showed the $\mathrm{Zn}$-coated sample underwent a reduction in strength that was most evident at a welding current of $7 \mathrm{kA}$. However, the decrease was not due to the presence of LME cracks, but the smaller nugget diameter of the coated samples correlated well with lower strength. The difference in strength of coated and uncoated samples with similar nugget diameters was caused by an increase in the stress concentration in the very thin layer of coating remaining in the weld notch.

Author Contributions: Conceptualization, V.K., C.D., L.H. and D.V.; data curation, V.K. and Z.Z.; funding acquisition, D.V.; investigation, V.K., Z.Z. and L.H.; methodology, V.K., C.D. and L.H.; project administration, D.V.; supervision, D.V.; visualization; V.K. and Z.Z.; writing-original draft preparation, V.K.; writing-review and editing, D.V. and C.D.; All authors have read and agreed to the published version of the manuscript.

Funding: This research was funded by a grant from Specific University Research Grant No A1_FCHT_2021_010.

Institutional Review Board Statement: Not applicable.

Informed Consent Statement: Not applicable.

Data Availability Statement: Data are contained within the article.

Conflicts of Interest: The authors declare no conflict of interest.

\section{References}

1. Shome, M.; Tumuluru, M. 1-Introduction to welding and joining of advanced high-strength steels (AHSS). In Welding and Joining of Advanced High Strength Steels (AHSS), 1st ed.; Shome, M., Tumuluru, M., Eds.; Woodhead Publishing: Sawston, UK, 2015; pp. 1-8.

2. Tamarelli, C.M. AHSS 101: The Evolving Use of Advanced High-Strength Steels for Automotive Applications; Materials Science and Engineering, University of Michigan: Ann Arbor, MI, USA, 2016; pp. 1-45. 
3. Saha, D.C.; Ji, C.W.; Park, Y.D. Coating behaviour and nugget formation during resistance welding of hot forming steels. Sci. Technol. Weld. Join. 2015, 20, 708-720. [CrossRef]

4. Hamedi, M.; Atashparva, M. A review of electrical contact resistance modeling in resistance spot welding. Weld. World 2017, 61, 269-290. [CrossRef]

5. Kimchi, M.; Phillips, D. Resistance Spot Welding: Fundamentals and Applications for the Automotive Industry, 1st ed.; Morgan \& Claypool: Williston, ND, USA, 2017; Volume 1, p. i-115.

6. Ertek Emre, H.; Kaçar, R. Resistance Spot Weldability of Galvanize Coated and Uncoated TRIP Steels. Metals 2016, 6, 299. [CrossRef]

7. Ighodaro, O.L.-R.; Biro, E.; Zhou, Y.N. Study and Applications of Dynamic Resistance Profiles during Resistance Spot Welding of Coated Hot-Stamping Steels. Metall. Mater. Trans. A 2017, 48, 745-758. [CrossRef]

8. $\quad$ Ling, Z.; Chen, T.; Kong, L.; Wang, M.; Pan, H.; Lei, M. Liquid Metal Embrittlement Cracking during Resistance Spot Welding of Galvanized Q\&P980 Steel. Metall. Mater. Trans. A 2019, 50, 5128-5142. [CrossRef]

9. DiGiovanni, C.; Kalashami, A.G.; Biro, E.; Zhou, N.Y. Liquid metal embrittlement transport mechanism in the Fe/Zn system: Stress-assisted diffusion. Materialia 2021, 18, 101153. [CrossRef]

10. Cho, L.; Kang, H.; Lee, C.; De Cooman, B.C. Microstructure of liquid metal embrittlement cracks on Zn-coated 22MnB5 press-hardened steel. Scr. Mater. 2014, 90-91, 25-28. [CrossRef]

11. Karbasian, H.; Tekkaya, A.E. A review on hot stamping. J. Mater. Process. Technol. 2010, 210, 2103-2118. [CrossRef]

12. Kurz, T.; Larour, P.; Lackner, J.; Steck, T.; Jesner, G. Press-hardening of zinc coated steel-characterization of a new material for a new process. IOP Conf. Ser. Mater. Sci. Eng. 2016, 159, 012025. [CrossRef]

13. Bhattacharya, D. Liquid metal embrittlement during resistance spot welding of Zn-coated high-strength steels. Mater. Sci. Technol. 2018, 34, 1809-1829. [CrossRef]

14. Razmpoosh, M.H.; DiGiovanni, C.; Zhou, Y.N.; Biro, E. Pathway to understand liquid metal embrittlement (LME) in Fe-Zn couple: From fundamentals toward application. Prog. Mater. Sci. 2021, 121, 100798. [CrossRef]

15. Arndt, M.; Truglas, T.; Duchoslav, J.; Hingerl, K.; Stifter, D.; Commenda, C.; Haslmayr, J.; Kolnberger, S.; Faderl, J.; Groiss, H. The Role of Grain Boundary Wetting for Metal Induced Embrittlement in Press Hardened Galvanized 20MnB8 Steel: A Nanoscale Investigation. arXiv 2020, arXiv:2007.01136.

16. Kang, H.; Cho, L.; Lee, C.; De Cooman, B.C. Zn Penetration in Liquid Metal Embrittled TWIP Steel. Metall. Mater. Trans. A 2016, 47, 2885-2905. [CrossRef]

17. Han, K.; Ohnuma, I.; Okuda, K.; Kainuma, R. Experimental determination of phase diagram in the Zn-Fe binary system. J. Alloys Compd. 2018, 737, 490-504. [CrossRef]

18. Lejček, P.; Šandera, P.; Horníková, J.; Pokluda, J.; Godec, M. On the segregation behavior of tin and antimony at grain boundaries of polycrystalline bcc iron. Appl. Surf. Sci. 2016, 363, 140-144. [CrossRef]

19. Herzig, C.; Mishin, Y. Grain Boundary Diffusion in Metals. In Diffusion in Condensed Matter, 2nd ed.; Heitjans, P., Kärger, J., Eds.; Springer: Berlin/Heidelberg, Germany, 2005; pp. 337-366.

20. Razmpoosh, M.H.; Macwan, A.; Goodwin, F.; Biro, E.; Zhou, Y. Crystallographic study of liquid-metal-embrittlement crack path Mater. Lett. 2020, 267, 127511. [CrossRef]

21. DiGiovanni, C.; Biro, E.; Zhou, N.Y. Impact of liquid metal embrittlement cracks on resistance spot weld static strength. Sci. Technol. Weld. Join. 2019, 24, 218-224. [CrossRef]

22. Razmpoosh, M.H.; Langelier, B.; Marzbanrad, E.; Zurob, H.S.; Zhou, N.; Biro, E. Atomic-scale Investigation of Liquid-MetalEmbrittlement Crack-path: Revealing Mechanism and Role of Grain Boundary Chemistry. Acta Mater. 2021, $204,116519$. [CrossRef]

23. Choi, D.Y.; Sharma, A.; Uhm, S.H.; Jung, J.P. Liquid Metal Embrittlement of Resistance Spot Welded 1180 TRIP Steel: Effect of Electrode Force on Cracking Behavior. Met. Mater. Int. 2019, 25, 219-228. [CrossRef]

24. Kim, Y.G.; Kim, I.J.; Kim, J.S.; Chung, Y.I.; Du, Y.C. Evaluation of Surface Crack in Resistance Spot Welds of Zn-Coated Steel. Mater. Trans. 2014, 55, 171-175. [CrossRef]

25. Baker, M.A.; Gissler, W.; Klose, S.; Trampert, M.; Weber, F. Morphologies and corrosion properties of PVD Zn-Al coatings. Surf. Coat. Technol. 2000, 125, 207-211. [CrossRef]

26. Park, J.H.; Hagio, T.; Kamimoto, Y.; Ichino, R.; Lee, M.H. Enhancement of corrosion resistance by lamination of Mg film on Zn-55Al-1.6Si-coated steel by physical vapor deposition. Surf. Coat. Technol. 2020, 387, 125537. [CrossRef]

27. Ghanbari, Z. Fe-Zn Phase Evolution and Cracking Behavior in Zn-Coated Press-Hardened Steel. Ph.D. Thesis, Colorado School of Mines, Golden, CO, USA, 2017.

28. Lee, H.; Jo, M.C.; Sohn, S.S.; Kim, S.H.; Song, T.; Kim, S.K.; Kim, H.S.; Kim, N.J.; Lee, S. Microstructural evolution of liquid metal embrittlement in resistance-spot-welded galvanized TWinning-Induced Plasticity (TWIP) steel sheets. Mater. Charact. 2019, 147, 233-241. [CrossRef]

29. DiGiovanni, C.; Bag, S.; Mehling, C.; Choi, K.W.; Macwan, A.; Biro, E.; Zhou, N.Y. Reduction in liquid metal embrittlement cracking using weld current ramping. Weld. World 2019, 63, 1583-1591. [CrossRef]

30. Wintjes, E.; DiGiovanni, C.; He, L.; Biro, E.; Zhou, N.Y. Quantifying the link between crack distribution and resistance spot weld strength reduction in liquid metal embrittlement susceptible steels. Weld. World 2019, 63, 807-814. [CrossRef] 
31. Tamizi, M.; Pouranvari, M.; Movahedi, M. The Role of HAZ Softening on Cross-Tension Mechanical Performance of Martensitic Advanced High Strength Steel Resistance Spot Welds. Metall. Mater. Trans. A 2021, 52, 655-667. [CrossRef]

32. Li, Y.; Tang, H.; Lai, R. Microstructure and Mechanical Performance of Resistance Spot Welded Martensitic Advanced High Strength Steel. Processes 2021, 9, 1021. [CrossRef]

33. Zhao, Y.; Zhang, Y.; Lai, X. Analysis of Fracture Modes of Resistance Spot Welded Hot-Stamped Boron Steel. Metals 2018, 8, 764. [CrossRef]

34. Tamizi, M.; Pouranvari, M.; Movahedi, M. Welding metallurgy of martensitic advanced high strength steels during resistance spot welding. Sci. Technol. Weld. Join. 2017, 22, 327-335. [CrossRef]

35. Marder, A.R. The metallurgy of zinc-coated steel. Prog. Mater. Sci. 2000, 45, 191-271. [CrossRef]

36. DiGiovanni, C.; He, L.; Pistek, U.; Goodwin, F.; Biro, E.; Zhou, N.Y. Role of spot weld electrode geometry on liquid metal embrittlement crack development. J. Manuf. Process. 2020, 49, 1-9. [CrossRef]

37. Ma, Y.; Yu, Y.; Geng, P.; Ihara, R.; Maeda, K.; Suzuki, R.; Suga, T.; Ma, N. Fracture modeling of resistance spot welded ultra-high-strength steel considering the effect of liquid metal embrittlement crack. Mater. Des. 2021, 210, 110075. [CrossRef]

38. Pouranvari, M.; Sobhani, S.; Goodarzi, F. Resistance spot welding of MS1200 martensitic advanced high strength steel: Microstructure-properties relationship. J. Manuf. Process. 2018, 31, 867-874. [CrossRef]

39. Ma, Y.; Takikawa, A.; Nakanishi, J.; Doira, K.; Shimizu, T.; Lu, Y.; Ma, N. Measurement of local material properties and failure analysis of resistance spot welds of advanced high-strength steel sheets. Mater. Des. 2021, 201, 109505. [CrossRef]

40. Sherepenko, O.; Kazemi, O.; Rosemann, P.; Wilke, M.; Halle, T.; Jüttner, S. Transient Softening at the Fusion Boundary of Resistance Spot Welds: A Phase Field Simulation and Experimental Investigations for Al-Si-coated 22MnB5. Metals 2020, 10, 10. [CrossRef]

41. Sherepenko, O.; Jüttner, S. Transient softening at the fusion boundary in resistance spot welded ultra-high strengths steel 22MnB5 and its impact on fracture processes. Weld. World 2019, 63, 151-159. [CrossRef]

42. DiGiovanni, C.; Han, X.; Powell, A.; Biro, E.; Zhou, N.Y. Experimental and Numerical Analysis of Liquid Metal Embrittlement Crack Location. J. Mater. Eng. Perform. 2019, 28, 2045-2052. [CrossRef] 